\title{
EVALUATION OF DOWNSCALED CMIP5 CLIMATE MODELS TO SELECT THE BEST MODELS TO DEVELOP FUTURE CLIMATE SCENARIOS FOR SRI LANKA
}

\author{
H.M.R.C. Herath ${ }^{1 *}$ and I.M.S.P. Jayawardena ${ }^{2}$ \\ Department of Meteorology, Sri Lanka
}

\begin{abstract}
Due to coarse resolution of global climate models, techniques are often needed to generate finer scale projections of variables affected by local-scale processes such as temperature and precipitation. Downscaling is widely used to improve spatial and/or temporal distributions of meteorological variables from regional and global climate models. This downscaling is important because climate models are spatially coarse (100$200 \mathrm{~km}$ ) and often misrepresent extremes in important meteorological variables, such as temperature and precipitation.NASA Earth Exchange Global Daily Downscaled Projections data with $25 \mathrm{~km}$ grid spacing and Coordinated Regional Climate Downscaling Experiment (CORDEX) data with $50 \mathrm{~km}$ grid spacing of $6 \mathrm{GCM}$ models were used to evaluate models suitability for Sri Lanka. Annual mean precipitation and seasonal mean precipitation for four climatic seasons namely Southwest Monsoon, Northeast Monsoon, First Inter monsoon and Second Inter-Monsoon, of model historical runs (1975-2005) were compared with observed climatological average of precipitation to evaluate the models' performance.

CORDEX downscaled models were unable to capture the bi-modal pattern of annual cycle of precipitation in Sri Lanka and the spatial pattern of precipitation.

NEX-GDDP downscaled models captured the bi-modal pattern of annual cycle of precipitation in Sri Lanka and the spatial pattern of precipitation of annual average as well as seasonal average.Based on the model performance of historical runs NASA Earth Exchange Global Daily Downscaled Projections of 6 GCM models (CanESM2, CNRMCM5, CSIRO-MK3-6-0, GFDL-CM3, MRI-CGCM3and NCAR-CCSM4) with 25km grid spacing were selected to develop future projections for Sri Lanka.
\end{abstract}

Keywords: downscaling, temperature, precipitation, seasonal, monsoon, annual, NEXGDDP, CORDEX

\section{Introduction}

\section{Introduction of general circulation models (GCMs)}

General circulation models (GCMs) are the primary tool for understanding how the global climate may change in the future but local scale precipitation processes are poorly represented due to the coarse resolution of the GCMs For climate change impact assessments finer scale information is required (Maraun et al, 2010). 
So-called 'downscaling' techniques have subsequently emerged as a means of bridging the gap between what climate modellers are currently able to provide and what impact assessors require (Wilby and Wigley, 1997). The two approaches of downscaling are Dynamical downscaling nests a regional climate model (RCM) into the GCM to represent the atmospheric physics with a higher grid box resolution within a limited area of interest and Statistical downscaling establishes statistical links between large-scale weather and observed local-scale weather (Maraun et al, 2010).

The NEX-GDDP dataset is comprised of downscaled climate scenarios for the globe that are derived from the General Circulation Model (GCM) runs conducted under the Coupled Model Intercomparison Project Phase 5 (CMIP5) [Taylor et al. 2012] and across two of the four greenhouse gas emissions scenarios known as Representative Concentration Pathways (RCPs) [Meinshausen et al. 2011]. The CMIP5 GCM runs were developed in support of the Fifth Assessment Report of the Intergovernmental Panel on Climate Change (IPCC AR5). This dataset includes downscaled projections from the 21 models and scenarios for which daily scenarios were produced and distributed under CMIP5 (Thrasher and Nemani, 2015).

The Bias-Correction Spatial Disaggregation (BCSD) method used in generating the NEX-GDDP dataset (Thrasher and Nemani, 2015) is a statistical downscaling algorithm specifically developed to address these current limitations of global GCM outputs [Wood et al. 2002; Wood et al. 2004; Maurer et al. 2008 ; Thrasher et al. 2012].

The dataset compiles 42 climate projections from 21 CMIP5 GCMs and two RCP scenarios (RCP 4.5 and RCP 8.5) for the period from 2006 to 2100 as well as the historical experiment for each model for the period from 1950 - 2005. Each of these climate projections is downscaled at a spatial resolution of 0.25 degrees $\mathrm{x}$ 0.25 degrees (Thrasher and Nemani, 2015).

CORDEX aims to foster international collaboration in order to generate an ensemble of high-resolution historical and future climate projections at regional scale, by downscaling different Global Climate Models (GCMs) participating in the Coupled Model Intercomparison Project Phase 5 (CMIP5) (Taylor et al. 2012).

The Coordinated Regional Downscaling Experiment (CORDEX), after applying

dynamical downscaling methods, downscaled climate data at a spatial resolution of 0.5 degrees x 0.5 degrees. (Giorgi et al, 2009)

\section{Introduction of general climatology of Sri Lanka}

The Climate of Sri Lanka is essentially monsoonal, dominated by the Southwest and Northeast monsoons, on which the life and economy of the island is critically dependent. The variations in air temperature are small except in the mountanaous area, where the rainfall variations are large. The significant anomalies in climate are mainly decided by the temporal and spatial variations of rainfall, which have a strong impact on agricultural activities in the Country.

Orography plays an important role in the rainfall distribution of Sri Lanka (Figure 1). The central part of the southern half of the island is mountainous with heights of more than $2500 \mathrm{~m}$ above the mean sea level.

The two monsoons essentially determine the seasonality of Sri Lanka since the temperature shows significant variation throughout the year. The seasons are distinguished only by means of the timing of the two monsoons and the transitional periods separating them, called inter-monsoon seasons (Chandrapala 1996). The Southwest monsoon is from May to September and the Northeast monsoon from December to February. The intermonsoon periods are from March to April and from October to November.

Objective of this study is to identify the most suitable downscale method to develop future climate projections to Sri Lanka. 


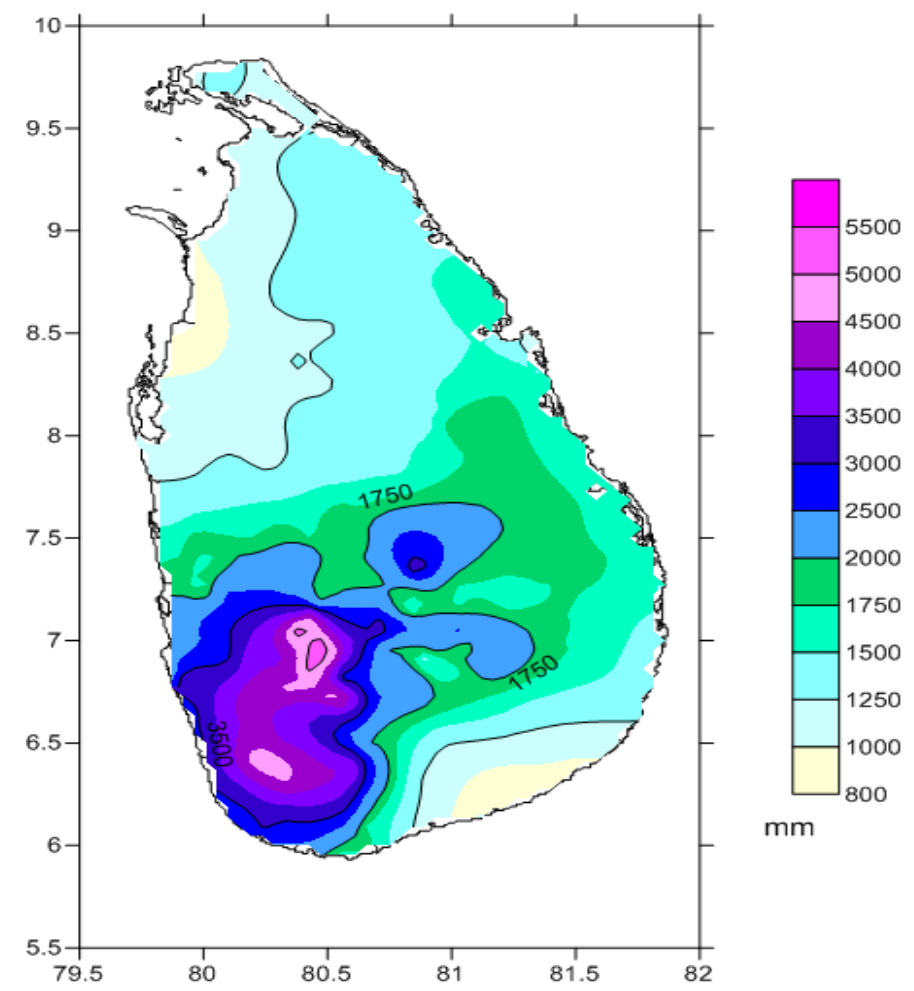

Figure. 1 Annual rainfall distribution (mm)

\section{Data and Methodology}

\section{GCM and downscaled products from CORDEX and NEX-NASA}

Climate Data Sharing and Analysis System (CDAAS) developed and maintained by RIMES, is a simple web based portal to access different Global Climate models and downscaled regional climate model products. CDAAS web portal is used to extract downscaled data from NEX-GDDP and CORDEX for the Sri Lanka region.

NASA Earth Exchange Global Daily Downscaled Projections (NEX-GDDP) dataset is comprised of downscaled climate scenarios for the globe that are derived from the General Circulation Model (GCM) runs conducted under the CMIP5 and across two of the four greenhouse gas emissions scenarios known as Representative Concentration Pathways (RCPs). The CMIP5 GCM runs were developed in support of the Fifth Assessment Report of the Intergovernmental Panel on Climate Change (IPCC AR5). The NEX-GDDP dataset includes downscaled projections for RCP 4.5 and RCP 8.5. 
H.M.R.C. Herath and I.M.S.P. Jayawardena / Evaluation of downscaled CMIP5 climate models to...

\begin{tabular}{|c|c|}
\hline \multicolumn{2}{|c|}{ Table 1 Earth System models used to evaluate } \\
\hline CanESM2 & $\begin{array}{l}\text { The Second Generation Coupled Global Climate Model } \\
\text { Canadian Centre for Climate Modelling and Analysis }(2.8 * 2.8)\end{array}$ \\
\hline CNRM-CM5 & National Centre for Meteorological Research/ Meteo-France $(1.4 * 1.4)$ \\
\hline CSIRO-MK3-6-0 & $\begin{array}{l}\text { Commonwealth Scientific and Industrial Research Organisation (CSIRO) and the } \\
\text { Queensland Climate Change Centre of Excellence (QCCCE). }(1.895 * 1.875)\end{array}$ \\
\hline \multicolumn{2}{|l|}{$\begin{array}{l}\text { CSIRO-CCAM- } \\
\text { ACCESS-1 }\end{array}$} \\
\hline GFDL-CM3 & $\begin{array}{l}\text { GeoPhysical Fluid Dynamic Laboratory NOAA, USA Coupled Climate Model ( } 2 \text { * } \\
\text { 2.5) }\end{array}$ \\
\hline MRI-CGCM3 & $\begin{array}{l}\text { Global Climate Model of the Meteorological Research Institute, Japan } \\
(1.132 * 1.125)\end{array}$ \\
\hline NCAR-CCSM4 & $\begin{array}{l}\text { National Center for Atmospheric Research, USA } \\
\text { Coupled Climate Model }(0.942 * 1.25)\end{array}$ \\
\hline $\begin{array}{l}\text { MPI-ESM-LR\& } \\
\text { MPI-ESM-MR }\end{array}$ & Max Planck Institute for Meteorology (MPI-M) \\
\hline MIROC5 & $\begin{array}{l}\text { Atmosphere and Ocean Research Institute (The University of Tokyo), National } \\
\text { Institute for Environmental Studies, and Japan Agency for Marine-Earth Science } \\
\text { and Technology }\end{array}$ \\
\hline
\end{tabular}

COordinated Regional Climate Downscaling Experiment (CORDEX) produced an ensemble of multiple dynamical downscaling models considering multiple forcing GCMs from the CMIP5 with $50 \mathrm{~km}$ grid spacing.

NASA Earth Exchange Global Daily Downscaled Projections data of 6 GCM models (CanESM2, CNRMCM5, CSIRO-MK3-6-0, GFDL-CM3, MRI-CGCM3and NCAR-CCSM4) with 25km grid spacing and CORDEX data of 6 GCM models CSIRO-CCAM-ACCESS-1, CSIRO-CCAM-CCSM-4, CSIRO-CCAMGFDL-CM3,CSIRO-CCAM-MPI-ESM-LR, REMO2009-MPI-ESM-LR, and SMHI-RCA4-ICHEC-EC with $50 \mathrm{~km}$ grid spacing were used to evaluate models suitable for Sri Lanka.

Annual mean precipitation and seasonal mean precipitation for four climatic seasons namely Southwest Monsoon, Northeast Monsoon, First Inter monsoon and Second Inter-Monsoon, of model historical runs (1975-2005) were compared with observed climatological average of precipitation to evaluate the models' performance. Annual cycle of the climatological monthly mean precipitation, Maximum temperature and minimum temperatures of model historical runs (1975-2005) were compared with observed values.

\section{Results\& Discussion}

\section{CORDEX}

Comparison of baseline climatology (rainfall and temperatures) and evaluation using observed data sets (Figure 2) shows Monthly Variation of Model historical Precipitation of dynamical downscaling of CORDEX (1975-2005) (Blue Bars) and Observed Precipitation (Red Line)

Annual cycle of precipitation climatology in Sri Lanka shows bi model pattern with peaks around May and November (Figure 2, red line). 
It shows that the model ACCESS-1 is over estimating the rainfall during the months of July and August with $124 \%$ and $183 \%$ (Figure 2) with respect to the observed climatology and under estimating with nearly 30 40\%during the months of March April and May as well as during the months of October November and December

Similar results can be observedof the model CCSM_4 with 128\% and 172\% during the months of July and August and nearly $40 \%$ below estimations on April, October and November.

Monthly averaged precipitation of first nine months except July and August, of the GFDL_CM3model goes well with the observations. Difference of model climatology and observed climatology is round $0-40 \%$ but the rest of months goes totally away with the observations with significant departures. (Figure 2)

Similar results were observed over the model MPI-ESM-LR.

Figure 4 represents the spatial maps of annual and seasonal precipitation of Model historical Precipitation of dynamical downscaling of CORDEX (1975-2005). It is clearly seen that all the downscaled model data are unable to capture the spatial variations in the orographic rainfall during annual and southwest monsoon seasonal precipitation.

CORDEX downscaled models were unable to capture the bi-modal pattern of annual cycle of precipitation in Sri Lanka (Figure2\& 3) as well as the spatial pattern of precipitation (Figure4) .

Temperatures climatology(Figure 3) of all the CORDEX models were able to capture the temporal pattern but under estimated (about 10\%) in maximum temperature and over estimated(about 8\%) in the minimum temperature. Spatial features were captured up to some extent but not much acceptable level.

\section{NEX-GDDP models}

All the NEX-GDDP models (Figure 5) were able to capture the temporal pattern mostly within 0-20\% departures from the climatology except the months of August and September where the deviations are 50\%\& $48 \%$ respectively.

Further all the NEX-GDDP models were able to represent minimum temperatures very well with observed climatology. The maximum temperature slightly under estimated during the middle months of the annual cycle (Figure 6).

All the spatial maps of NEX-GDDP models were able to capture the orographic rainfall variation well compared with the observed climatology (Figure7). Spatial variations of maximum(Figure 8)and minimum (Figure 9) temperatures were also represented well compared with the observed climatology.

NEX-GDDP downscaled models were captured the bi-modal pattern of annual cycle of precipitation in Sri Lanka (Figure $5 \& 6$ ) as well as the spatial pattern of precipitation of annual average as well as seasonal average (Figure 7).

Multi Model ensemble of these six models (Figure 10) \& (Table 2) shows that models were slightly under estimated the January, February November and December Rainfall in 3-10\% and slightly over estimated during the rest of the months in 2-20\% except August and September (35-45\% over estimated) compared with the observed climatology. 


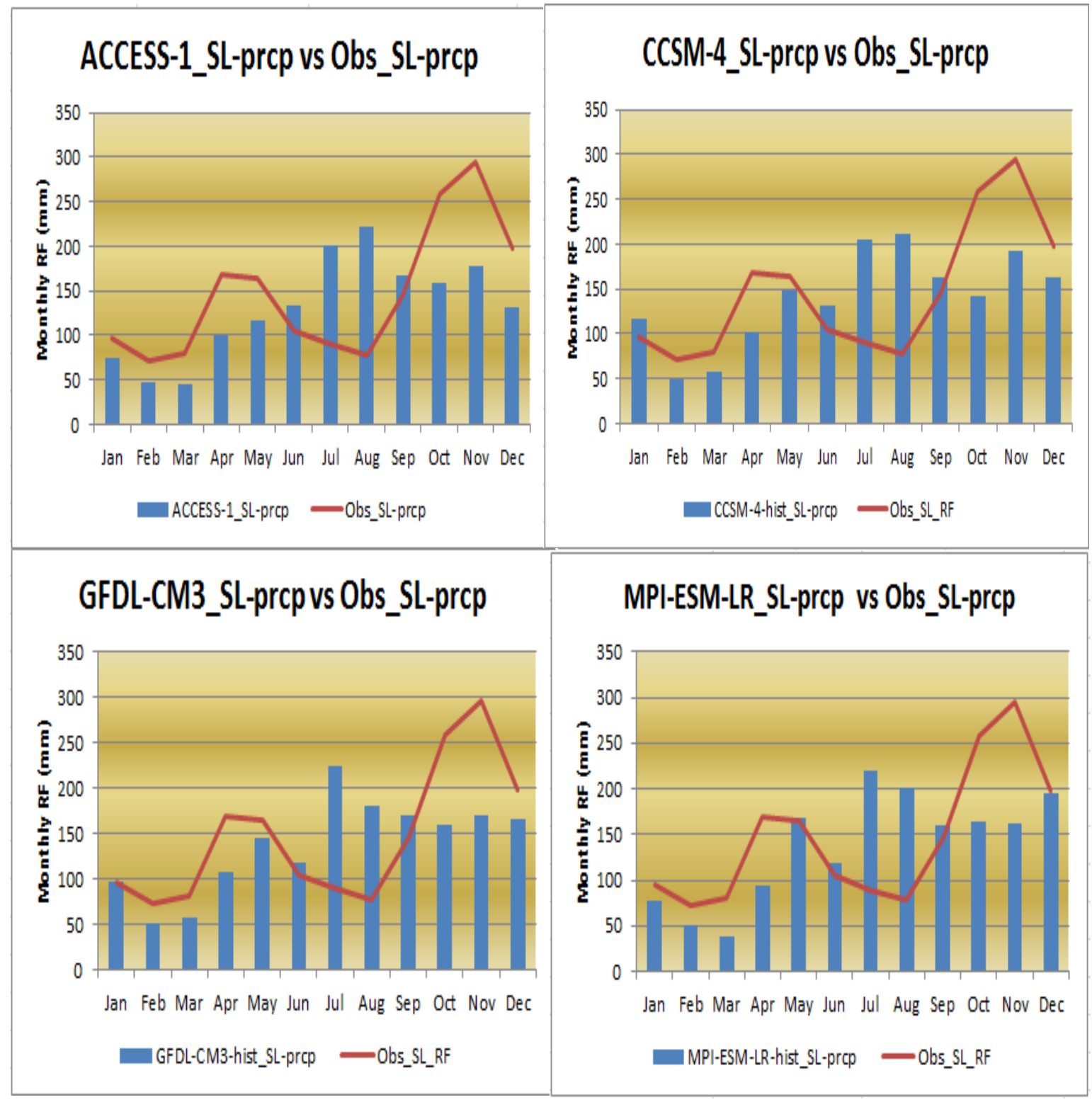

Figure2 : Monthly Variation of Model historical Precipitation of dynamical downscaling of CORDEX (1975-2005) (bars) Vs Observed Precipitation (Red Line) 
Monthly variation of Model historical Tmax and Tmin with Observed Tmax and Tmin
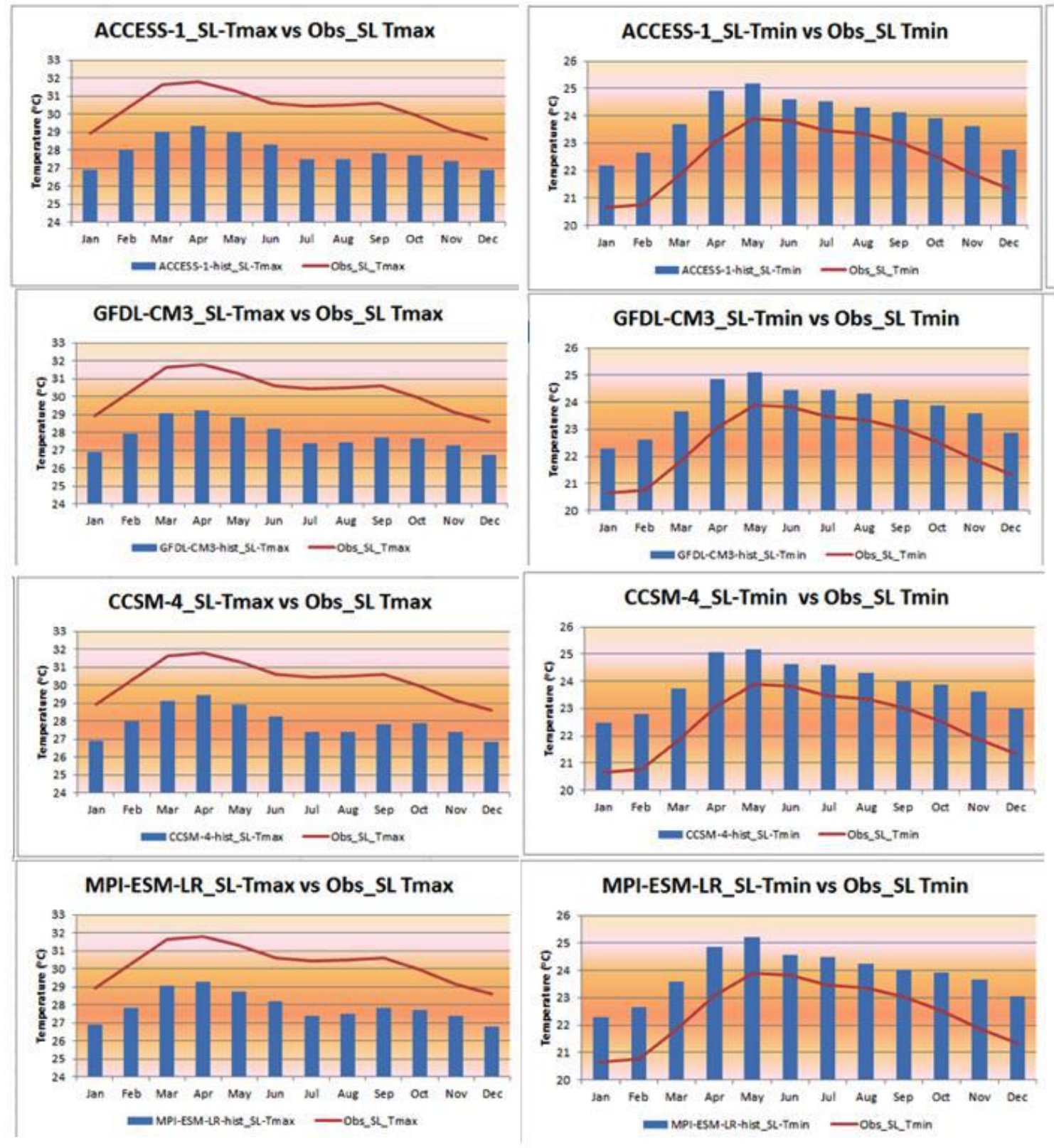

Figure3 : Monthly Variation of Model historical Maximum Temperature (Left) and Minimum Temperature (Right) of dynamical downscaling of CORDEX (1975-2005) (bars) Vs Observed Maximum Temperature (red line, left) and Observed Minimum Temperature (red line, Right) 
H.M.R.C. Herath and I.M.S.P. Jayawardena / Evaluation of downscaled CMIP5 climate models to...

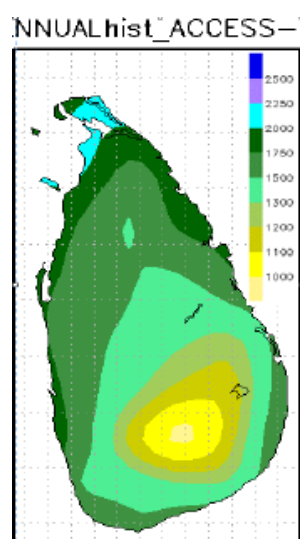

SWMhist_ACCESS -1
NNUALhist GFDL-CMNUALhist MPI-ESM-

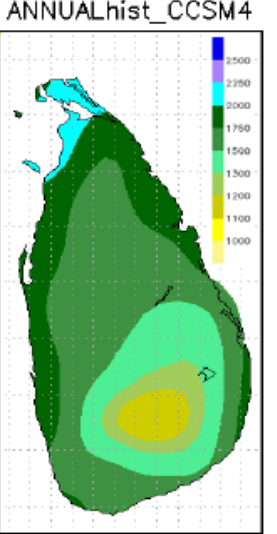

SWMhist CCSM4 iWM

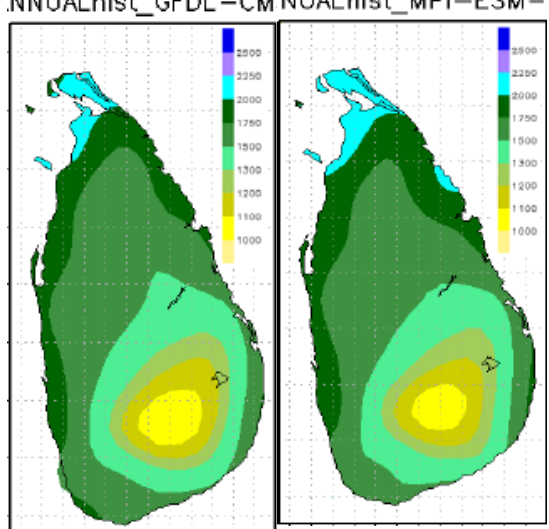

WM hist_MPI-ESM-LF SWM hist_GFDL-CM3
Annual Precipitation

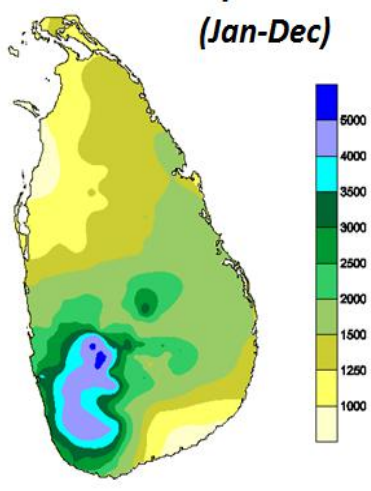

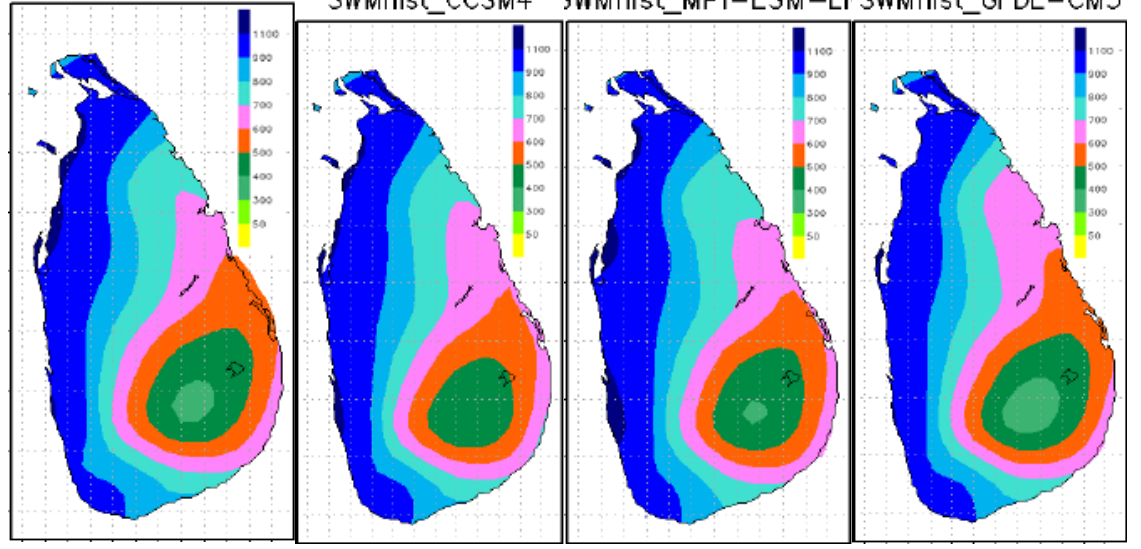

Southwest Monsoon

(May-Sept)
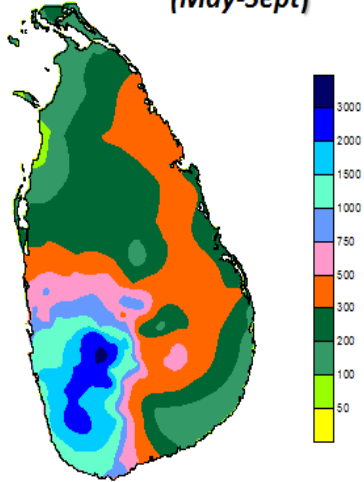

NEMhist_ACCESS-1 NEMhist_CCSM4 NEMhist_GFDL-CM3EMhist_MPI-ESM-LF

\section{Northeast Monsoon}
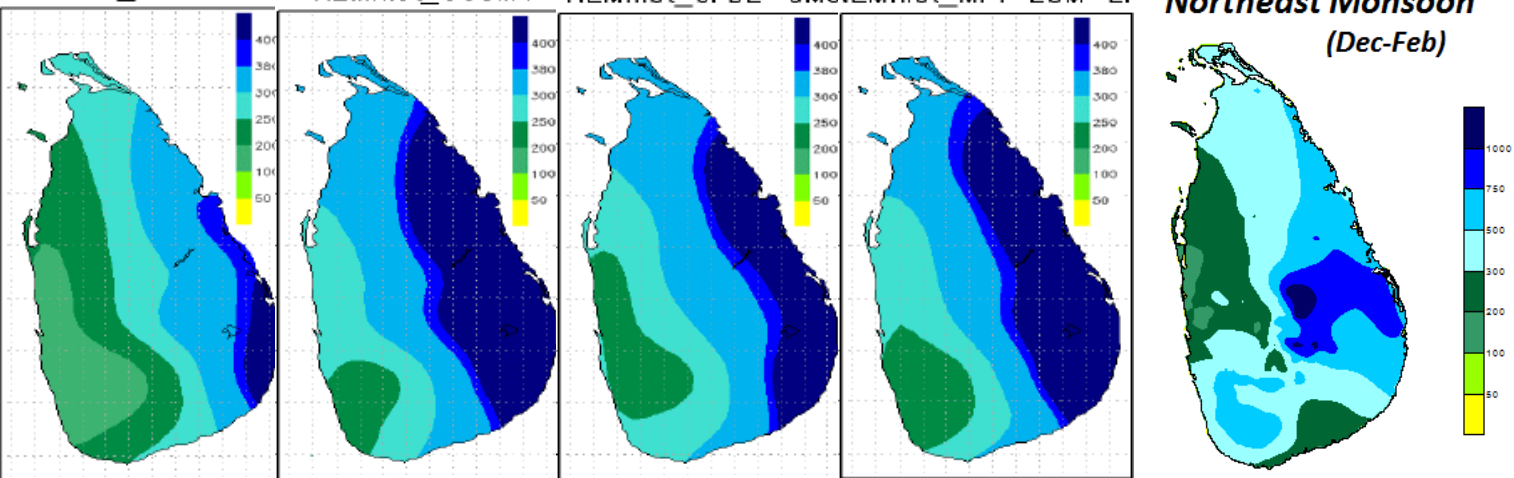

Figure4 : Spatial variation of Model historical precipitation of dynamical downscaling of CORDEX (1975-2005) Vs Observed precipitation of Annual average (Upper), Southwest Monsoon season (Middle) and Northeast Monsoon Season 

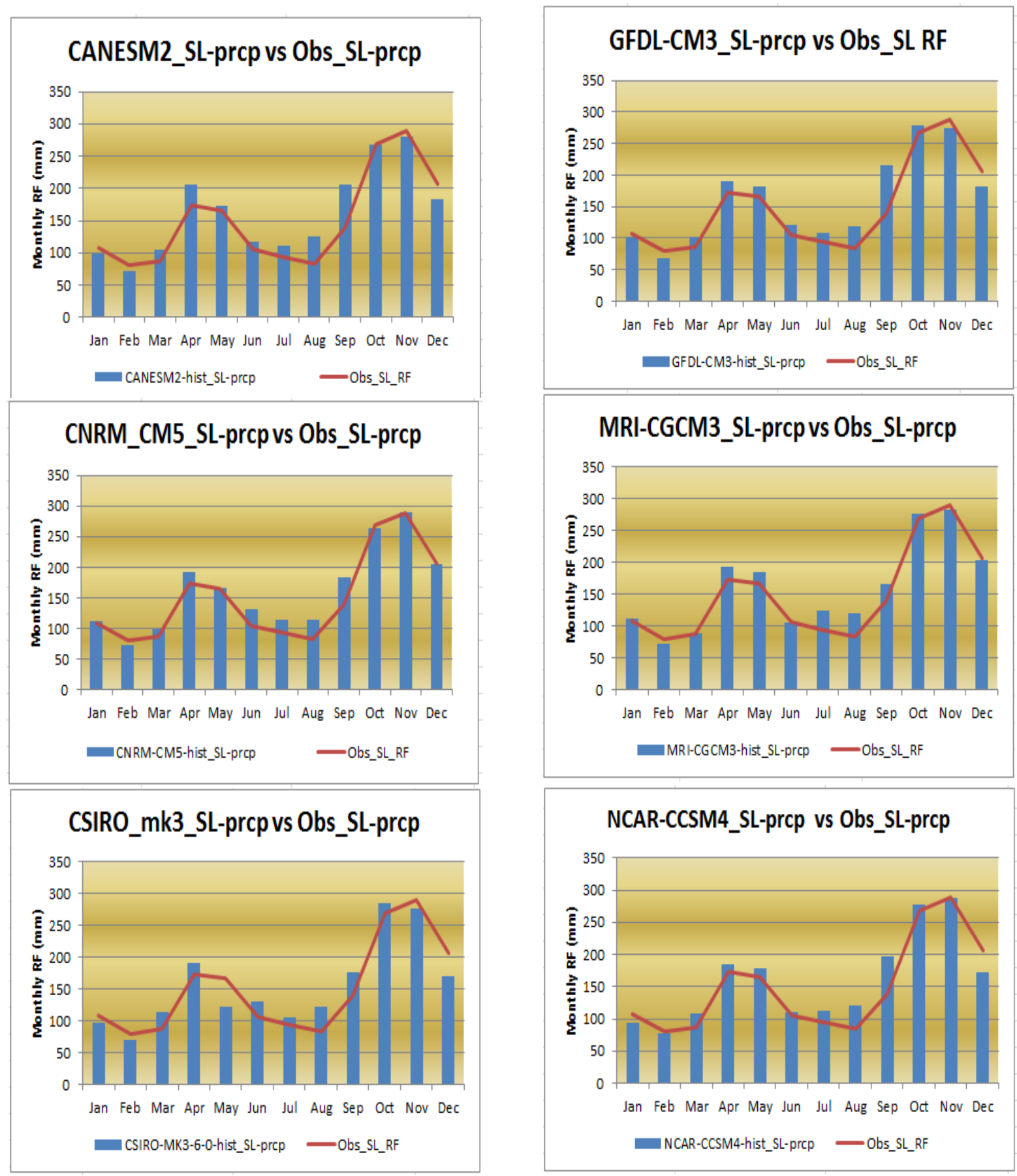

Figure5 : Monthly Variation of Model historical Precipitation of statistical downscaling of CORDEX (1975-2005) (bars) Vs Observed Precipitation (Red Line) 
H.M.R.C. Herath and I.M.S.P. Jayawardena / Evaluation of downscaled CMIP5 climate models to...
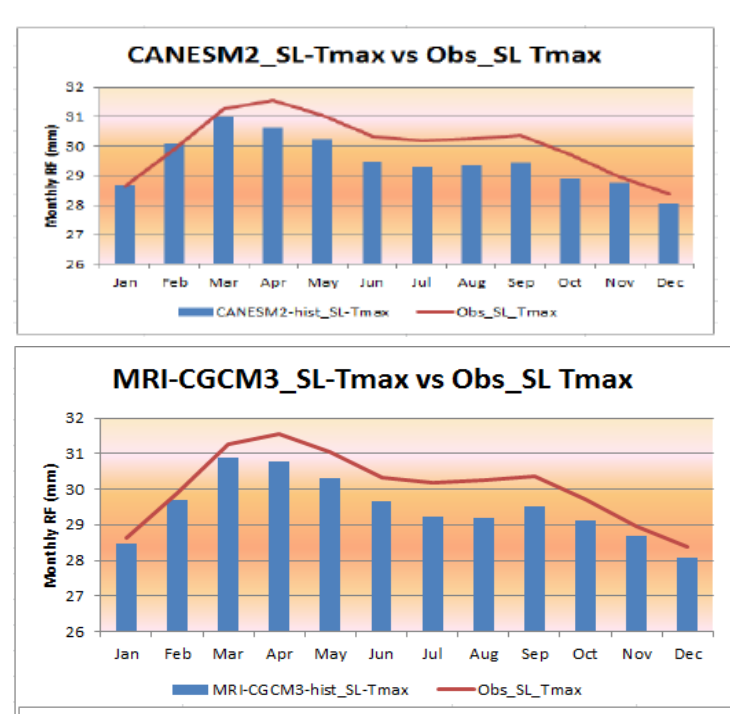

GFDL-CM3_SL-Tmax vs Obs_SL Tmax

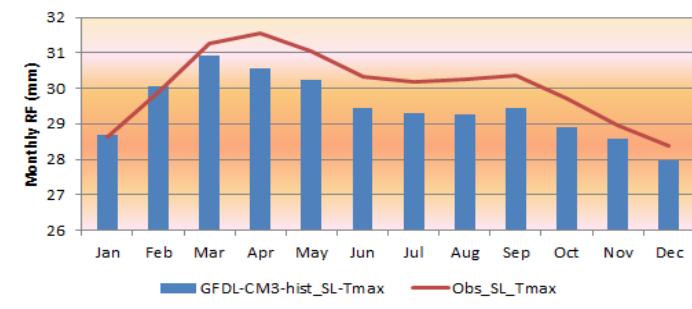

NCAR-CCSM4_SL-Tmax vs Obs_SL Tmax
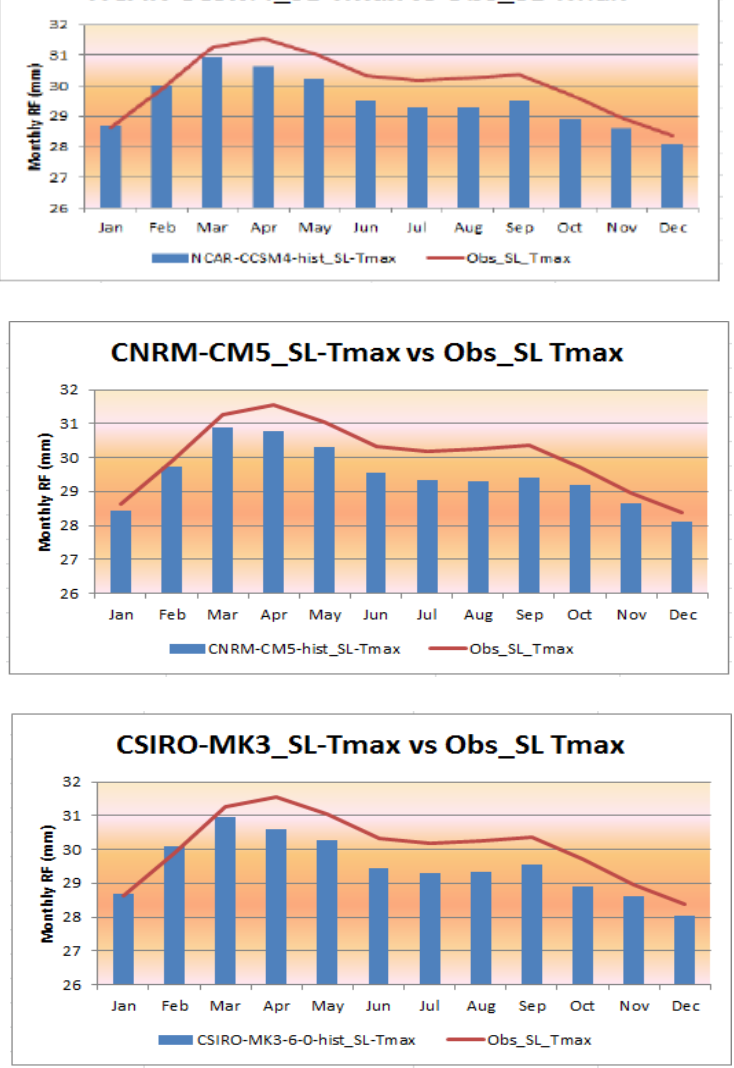
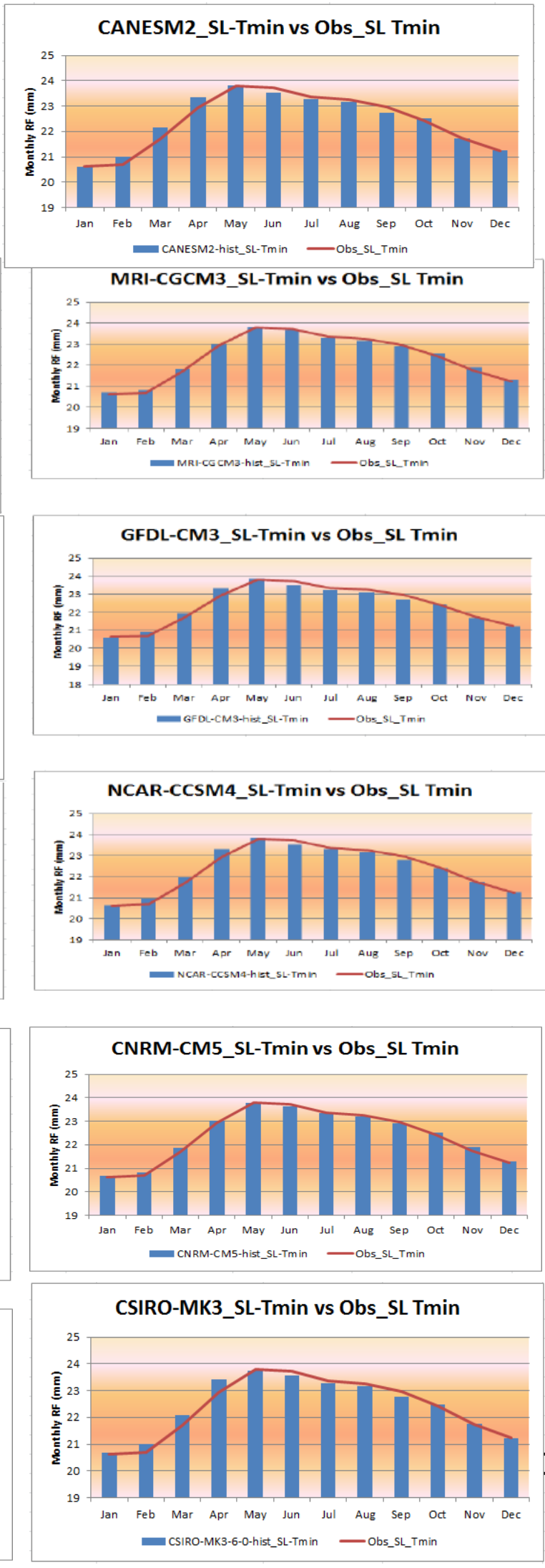

Figure 6 : Monthly Variation of Model historical Maximum Temperature (left) and Minimum Temperature (right) of statistical downscaling of NEX GDDP (1975-2005) (bars) Vs Observed Maximum and Minimum Temperature (red line) 

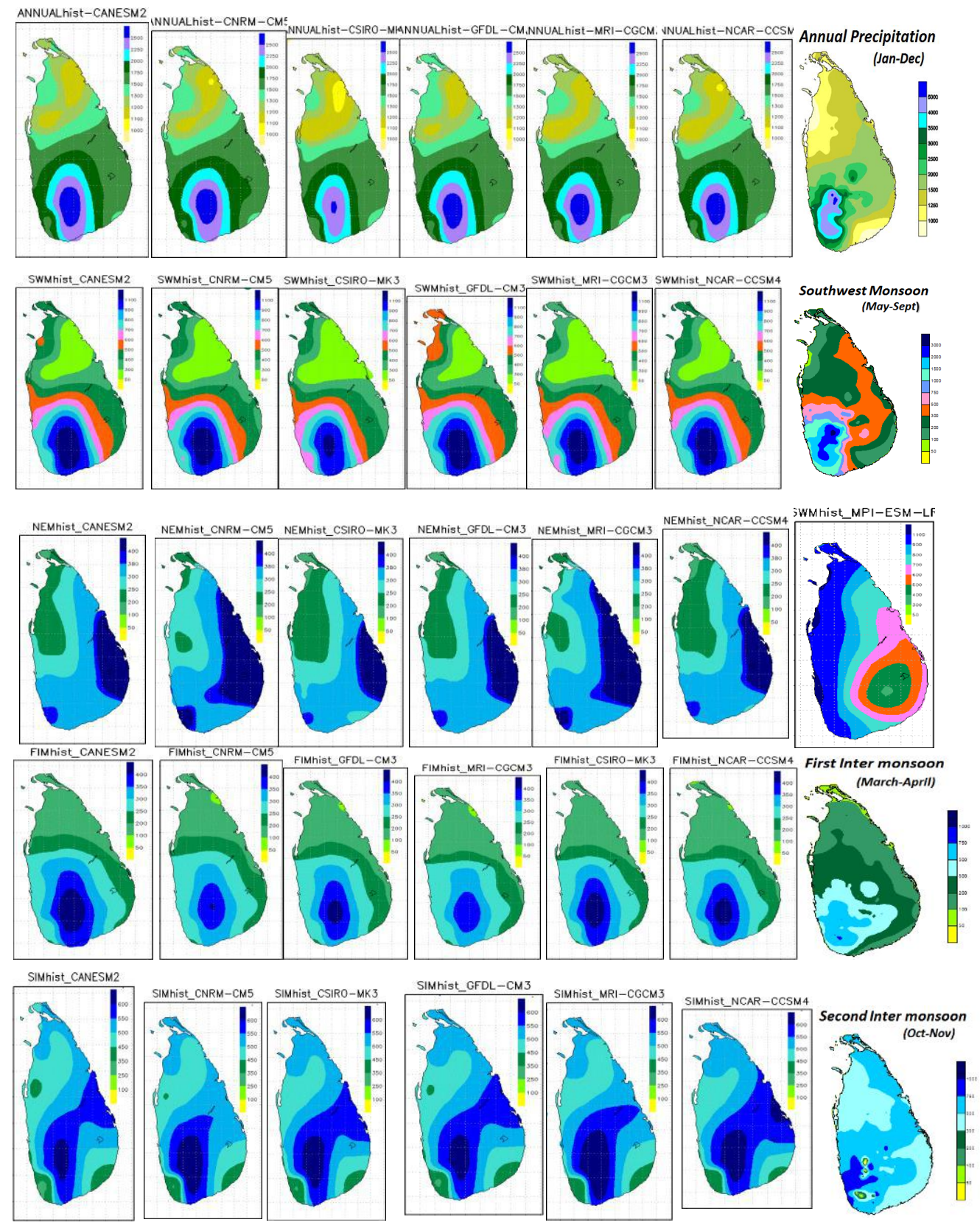

Figure 7 : Spatial variation of Model historical precipitation of Statistical downscaling of NEX-GDDP (1975-2005) Vs Observed precipitation of Annual average, Southwest Monsoon season and Northeast Monsoon Season, First Inter-monsoon season and Second Inter-monsoon season 
H.M.R.C. Herath and I.M.S.P. Jayawardena / Evaluation of downscaled CMIP5 climate models to...
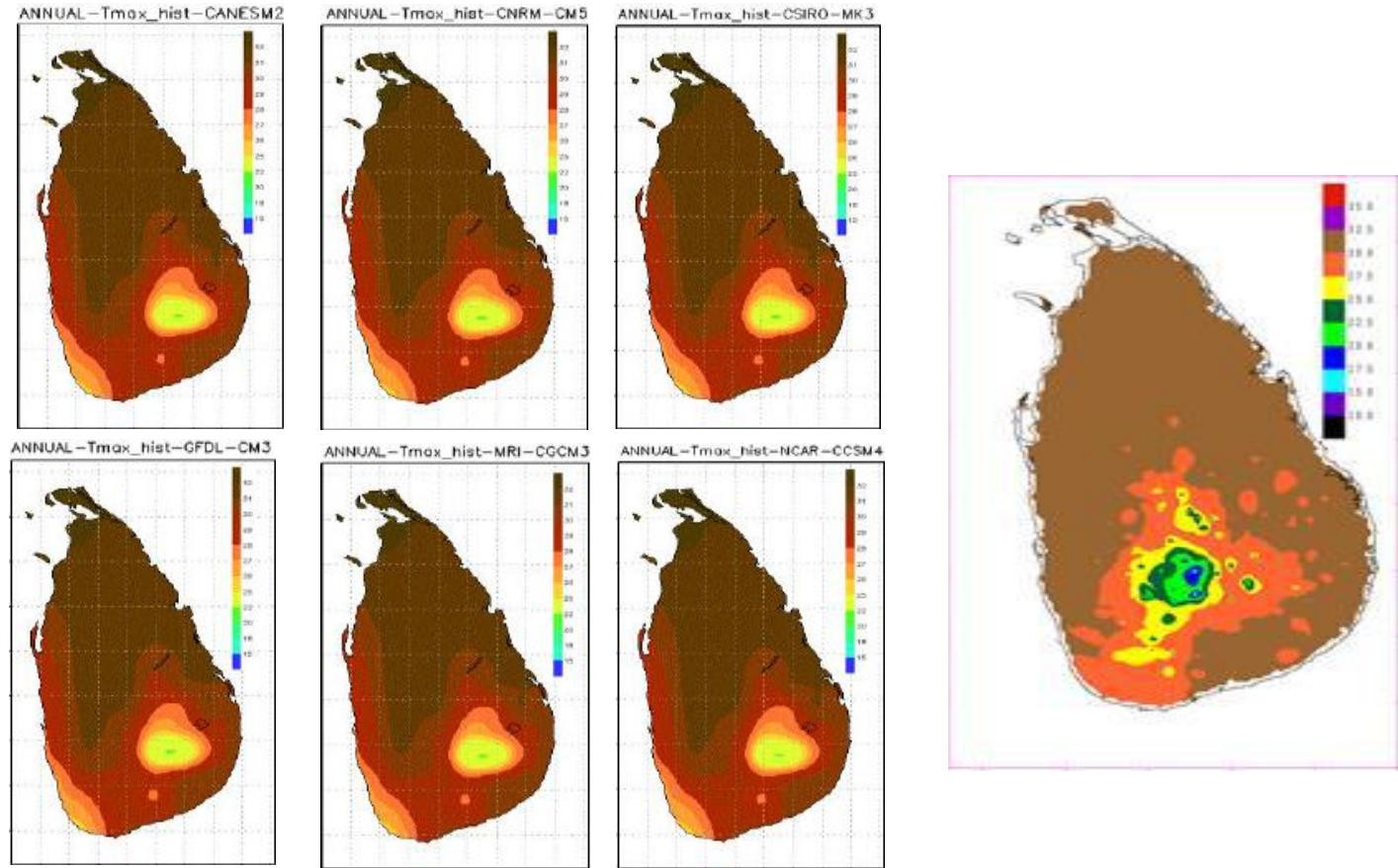

Figure 8 : Spatial variation of Model historical Maximum Temperature of Statistical downscaling of NEX-GDDP (19752005) Vs Observed Maximum Temperature of Annual average,

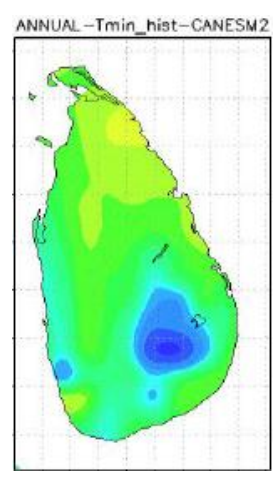

ANNUAL-TMin hist-GFD-CM3

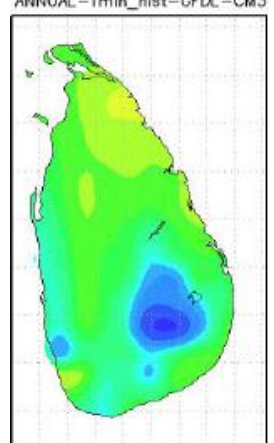

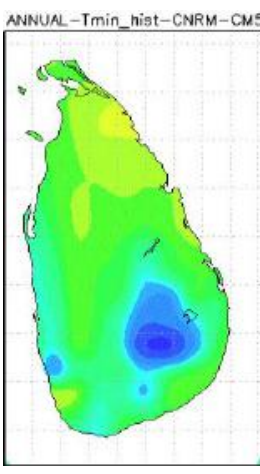
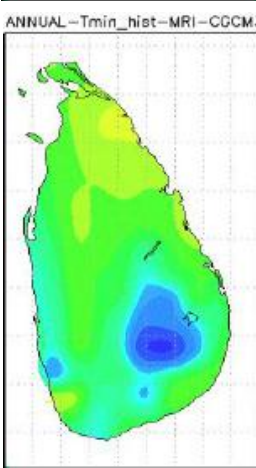
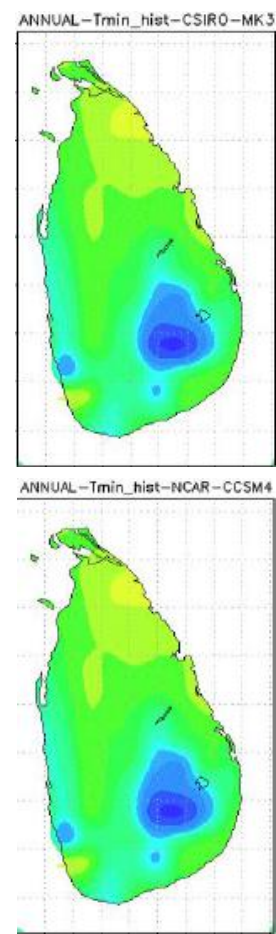

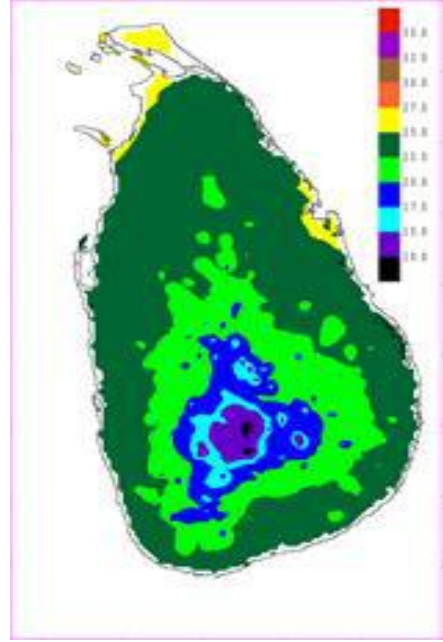

Figure 9 : Spatial variation of Model historical Minimum Temperature of Statistical downscaling of NEX-GDDP (19752005) Vs Observed Minimum Temperature of Annual average, 


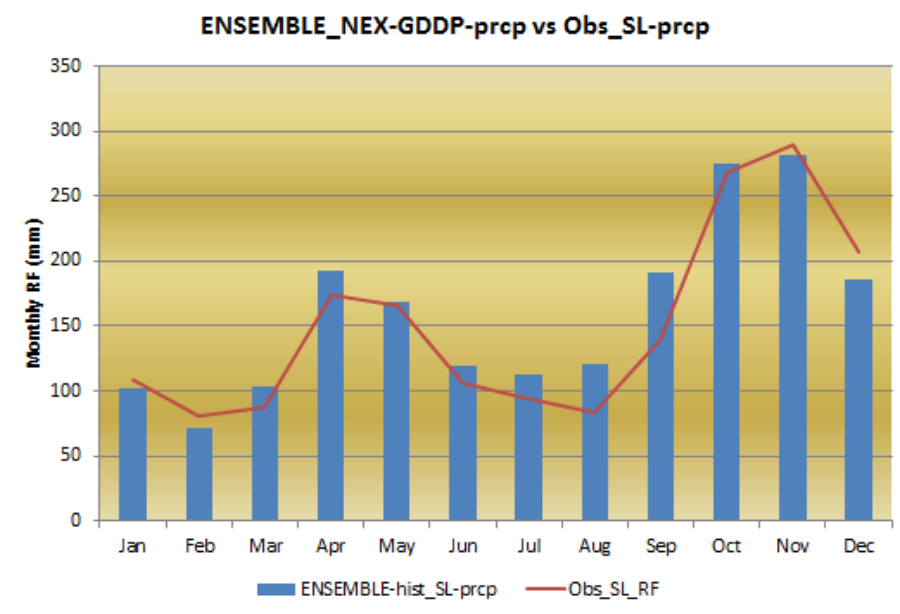

ENSEMBLE_NEX-GDDP-Tmax vs Obs_SL-Tmax

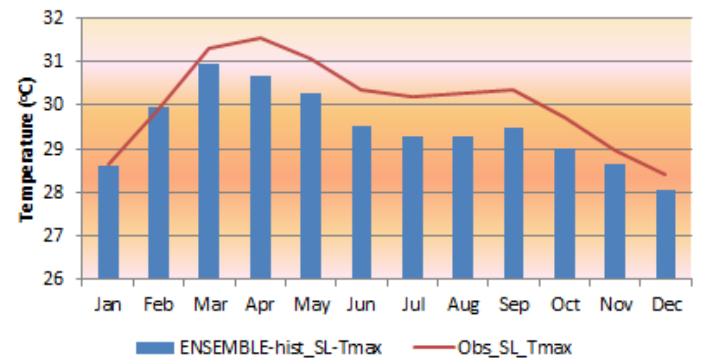

ENSEMBLE_NEX-GDDP-Tmin vs Obs_SL-Tmin

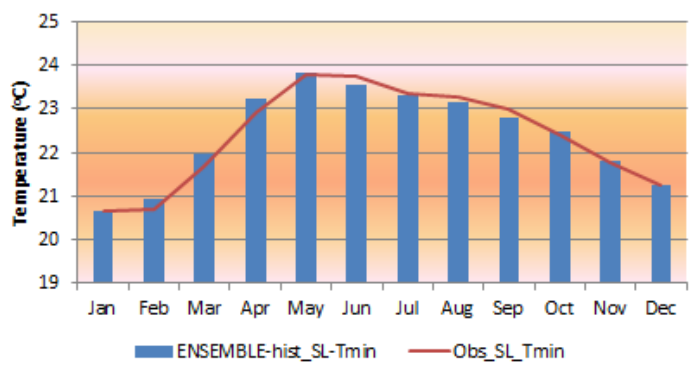

Figure 10 : Monthly Variation of Model historical precipitation (above), Maximum Temperature (left) and Minimum Temperature (right) of statistical downscaling of Ensemble NEX-GDDP (1975-2005) (bars) Vs Observed Maximum and Minimum Temperature (red line)

Table 2 - \% of departure_ENSEMBLE Climatology from Observed Climatology (Sri Lanka)

\begin{tabular}{|l|l|l|l|}
\hline & Precipitation & Tmax & Tmin \\
\hline Jan & $-6 \%$ & $0 \%$ & $0 \%$ \\
\hline Feb & $-10 \%$ & $0 \%$ & $1 \%$ \\
\hline Mar & $18 \%$ & $-1 \%$ & $1 \%$ \\
\hline Apr & $11 \%$ & $-3 \%$ & $1 \%$ \\
\hline May & $1 \%$ & $-3 \%$ & $0 \%$ \\
\hline Jun & $13 \%$ & $-3 \%$ & $-1 \%$ \\
\hline Jul & $19 \%$ & $-3 \%$ & $0 \%$ \\
\hline Aug & $44 \%$ & $-3 \%$ & $0 \%$ \\
\hline Sep & $37 \%$ & $-3 \%$ & $-1 \%$ \\
\hline Oct & $2 \%$ & $-2 \%$ & $0 \%$ \\
\hline Nov & $-3 \%$ & $-1 \%$ & $0 \%$ \\
\hline Dec & $-10 \%$ & $-1 \%$ & $0 \%$ \\
\hline Annual & $7 \%$ & $-2 \%$ & $0 \%$ \\
\hline
\end{tabular}




\section{Conclusion}

NASA Earth Exchange Global Daily Downscaled Projections data with $25 \mathrm{~km}$ grid spacing and Coordinated Regional Climate Downscaling Experiment (CORDEX) data with 50km grid spacing of 6 GCM models were used to evaluate models suitability for Sri Lanka. Annual mean precipitation and seasonal mean precipitation for four climatic seasons namely Southwest Monsoon, Northeast Monsoon, First Inter monsoon and Second Inter-Monsoon, of model historical runs (1975-2005) were compared with observed climatological average of precipitation to evaluate the models' performance.

CORDEX downscaled models were unable to capture the bi-modal pattern of annual cycle of precipitation in Sri Lanka and the spatial pattern of precipitation.

NEX-GDDP downscaled models captured the bi-modal pattern of annual cycle of precipitation in Sri Lanka and the spatial pattern of precipitation of annual average as well as seasonal average. Based on the model performance of historical runs NASA Earth Exchange Global Daily Downscaled Projections of 6 GCM models (CanESM2, CNRM-CM5, CSIRO-MK3-6-0, GFDL-CM3, MRI-CGCM3and NCAR-CCSM4) with $25 \mathrm{~km}$ grid spacing were selected to develop future projections for Sri Lanka.

Based on the model performance of historical runs NASA Earth Exchange Global Daily Downscaled Projections of 6 GCM models (CanESM2, CNRM-CM5, CSIRO-MK3-6-0, GFDL-CM3, MRI-CGCM3and NCAR-CCSM4) with $25 \mathrm{~km}$ grid spacing were used future projections for Sri Lanka.

\section{Acknowledgement}

Technical support provided by RIMES under the "Capacity building on generation and application of downscaled climate change projections" project funded by UN ESCAP Trust Fund for Tsunami, Disaster and Climate Preparedness in Indian Ocean and Southeast Asian Countries (LOA No. 2014-0036) is acknowledged.

\section{References}

Chandrapala, L., 1996. Long term trends of rainfall and temperature in Sri Lanka. Climate variability and agriculture, pp.153-162.

Giorgi, F., Jones, C. and Asrar, G.R., 2009. Addressing climate information needs at the regional level: the CORDEX framework. World Meteorological Organization (WMO) Bulletin, 58(3), p.175.

Hartmann, D.L., Tank, A.M.G.K. and Rusticucci, M., 2013. IPCC fifth assessment report, climate change 2013: The physical science basis. IPCC AR5, pp.31-39.

Maurer, E.P. and Hidalgo, H.G., 2008. Utility of daily vs. monthly large-scale climate data: an intercomparison of two statistical downscaling methods.

Maraun, D., Wetterhall, F., Ireson, A.M., Chandler, R.E., Kendon, E.J., Widmann, M., Brienen, S., Rust, H.W., Sauter, T., Themeß1, M. and Venema, V.K.C., 2010. Precipitation downscaling under climate change: Recent developments to bridge the gap between dynamical models and the end user. Reviews of Geophysics, 48(3).

Prudhomme, C., Reynard, N. and Crooks, S., 2002. Downscaling of global climate models for flood frequency analysis: where are we now?.Hydrological processes, 16(6), pp.1137-1150.

Thrasher, B. and Nemani, R., NEX-DCP30: Downscaled 30 Arc-Second CMIP5 Climate Projections for Studies of Climate Change Impacts in the United States 1. Intent of This Document and POC.

Taylor, K.E., Stouffer, R.J. and Meehl, G.A., 2012. An overview of CMIP5 and the experiment design. Bulletin of the American Meteorological Society, 93(4), pp.485-498.

Thrasher, B. and Nemani, R., NASA Earth Exchange Global Daily Downscaled Projections (NEX-GDDP) 2015 1.Intent of This Document and POC. ) 
Van Vuuren, D.P., Edmonds, J., Kainuma, M., Riahi, K., Thomson, A., Hibbard, K., Hurtt, G.C., Kram, T., Krey, V., Lamarque, J.F. and Masui, T., 2011. The representative concentration pathways: an overview. Climatic change, 109(1-2), p.5.

Wilby, R.L. and Wigley, T.M.L., 1997. Downscaling general circulation model output: a review of methods and limitations. Progress in physical geography, 21(4), pp.530-548.

Wood, A.W., Leung, L.R., Sridhar, V. and Lettenmaier, D.P., 2004. Hydrologic implications of dynamical and statistical approaches to downscaling climate model outputs. Climatic change, 62(1), pp.189-216. 